\title{
A New Tetraglycosylated Flavonoid from Leaves of Platycyamus regnellii Benth. Isolated by High-Speed Countercurrent Chromatography
}

\author{
Carla M. Leal, ${ }^{a}$ Ricardo M. Borges, ${ }^{a}$ Rosineide C. Simas, ${ }^{b}$ Fernanda N. Costa ${ }^{a}$ and \\ Gilda G. Leitão ${ }^{\circledR} * a$ \\ ${ }^{a}$ Instituto de Pesquisas de Produtos Naturais, Centro de Ciências da Saúde, \\ Universidade Federal do Rio de Janeiro, Bloco H, Ilha do Fundão, \\ 21540-902 Rio de Janeiro-RJ, Brazil \\ ${ }^{b}$ Faculdade de Farmácia, Centro de Ciências da Saúde, Universidade Federal do Rio de Janeiro, \\ Bloco A, Ilha do Fundão, 21941-902 Rio de Janeiro-RJ, Brazil
}

\begin{abstract}
A new tetraglycosylated flavonoid derivative of kaempferol was isolated from the butanol extract of leaves of Platycyamus regnellii (Fabaceae) using high-speed countercurrent chromatography (HSCCC). The butanol extract $(960.5 \mathrm{mg})$ was initially fractionated with the solvent system EtOAC-BuOH- $\mathrm{H}_{2} \mathrm{O}$ 2:8:10 (v/v/v) (elution in normal phase mode). The fractions containing the major tetraglycosylated flavonoid were further purified with the same solvent system by modifying the ratios to $3: 7: 10(\mathrm{v} / \mathrm{v} / \mathrm{v})$ and alternating the elution to reversed phase mode. The structure of the isolated flavonoid (48.1 mg, $99.7 \%$ purity by ultra-high performance liquid chromatography with diode array detector (UHPLC-DAD)) was characterized by spectrometric and spectroscopic methods and identified as kaempferol 3-O- $\beta$-D-glucopiranosyl- $(1 \rightarrow 2)-\alpha$-L-rhamnopiranoside- $(1 \rightarrow 6)-\alpha-\mathrm{L}$ rhamnopiranoside-7-O- $\alpha$-L-rhamnopiranoside. Other minor flavonoids were also detected and tentatively identified using ultra-high performance liquid chromatography with diode array detector coupled to mass spectrometry using the electrospray ionization interface (UHPLC-DAD-ESI-MS/ MS). By using the latter technique, a second tetraglycosylated flavonol with an $O$-methyl substituent (either rhamnetin, 3-O-methyl-quercetin or isorhamnetin) was detected, together with a triglycosylated kaempferol and diglycosylated flavonoids (either rhamnetin, 3- $O$-methyl-quercetin or isorhamnetin).
\end{abstract}

Keywords: Platycyamus regnellii, Fabaceae, countercurrent chromatography, tetraglycosylated flavonoid

\section{Introduction}

Platycyamus regnellii (Fabaceae), is popularly known in Brazil as "pau-pereira", "mangalô", "folha-de-bolo", "pau-pereira-amarela" and "pereira vermelha". ${ }^{1}$ It is largely distributed across the northeast, center-west, southeast and south of Brazil. ${ }^{2}$ Five flavonoids (vestitol, isoliquiritigenin, medicarpine, 7,4'-di-hydroxy-6-O-methyl flavan and 3'-hydroxy-7,4'-di- $O$-methyl isoflavone) were previously isolated from the dichloromethane extract of the roots of this species. ${ }^{1}$ No phytochemical investigations were made on the flavonoid composition of the leaves of this plant. This work focused on selection of solvent systems for the isolation of polar flavonoids from the butanol extract of $P$. regnellii leaves using high-speed countercurrent chromatography (HSCCC). This liquid-

*e-mail: ggleitao@ correio.nppn.ufrj.br liquid partition-based chromatography technique ${ }^{3,4}$ enabled the purification of the major compound from the butanol extract. The novel compound was identified as kaempferol 3-O- $\beta$-D-glucopiranosyl- $(1 \rightarrow 2)$ - $\alpha$-L-rhamnopiranoside$(1 \rightarrow 6)$ - $\alpha$-L-rhamnopiranoside-7- $O$ - $\alpha$-L-rhamnopiranoside (Figure 1). Furthermore, ultra-high performance liquid chromatography with diode array detector coupled to mass spectrometry using the electrospray ionization interface (UHPLC-DAD-ESI-MS/MS) acquired data lead to the identification of five minor compounds in this same extract (Figure 2).

\section{Experimental}

Reagents

Organic solvents used for extracts preparation, HSCCC separations, UHPLC-DAD-ESI-MS/MS and high resolution- 


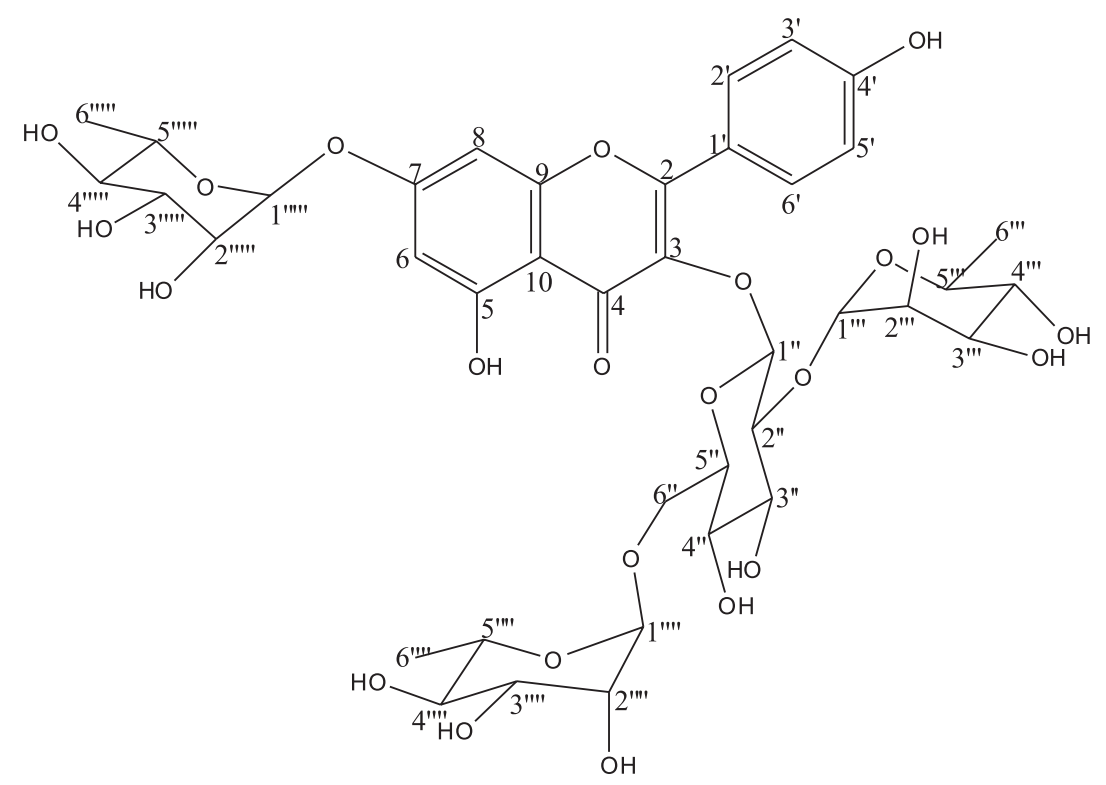

Figure 1. Kaempferol 3- $O$ - $\beta$-D-glucopiranosyl-( $1 \rightarrow 2)-\alpha$-L-rhamnopiranoside-( $1 \rightarrow 6)-\alpha$-L-rhamnopiranoside-7- $O$ - $\alpha$-L-rhamnopiranoside.<smiles></smiles>

Figure 2. Proposed aglycones for the minor flavonoids of the butanol extract. (1) Kaempferol, (2) 3-O-methyl-quercetin ether, (3) rhamnetin, (4) isorhamnetin.

electrospray ionization-Orbitrap-mass spectrometry (HR-ESI-Orbitrap-MS) analysis presented analytical grade and were purchased from Tedia (Tedia Brazil, Rio de Janeiro, Brazil). Aqueous solutions were prepared with pure water produced by Milli-Q water $(18.2 \mathrm{M} \Omega \mathrm{cm})$ system.

\section{Preparation of crude extract}

Leaves of $P$. regnellii $(2 \mathrm{~kg}$ ) were collected at Rio de Janeiro Botanical Gardens (Instituto de Pesquisas Jardim Botânico do Rio de Janeiro) in October 2011. The plant occurs at the arboretum of the park and was identified by A. Occhioni. A voucher specimen is deposited under the number RB00181650.

The dried and ground leaves were subjected to maceration with ethanol $96^{\circ} \mathrm{GL}$. The crude extract (30 g) was dissolved in methanol-water 3:7 (v/v) and submitted to liquid-liquid extraction to yield 5 fractions of increasing polarity: hexane $(8.3 \mathrm{~g}), \mathrm{CH}_{2} \mathrm{Cl}_{2}(1.3 \mathrm{~g})$, EtOAc (2.0 g), $\mathrm{BuOH}(8.0 \mathrm{~g})$ and the aqueous residue $(10.4 \mathrm{~g})$.

\section{UHPLC-DAD-ESI-MS/MS analysis}

Preliminary analysis of the butanol extract was performed using UHPLC-DAD-ESI-MS/MS unit resolution (Thermo Fisher Scientific, Germany) using a column Poroshell 120 EC-C18 $(2.1 \times 100 \mathrm{~mm}$ internal diameter (i.d.); $2.7 \mu \mathrm{m}$ particle size; Agilent, Santa Clara, USA) at $30{ }^{\circ} \mathrm{C}$. ESI ionization in negative mode, sheath gas flow rate: $40 \mathrm{arb}$, auxiliary gas flow rate: $10 \mathrm{arb}$, sweep gas flow rate: 0 arb, spray voltage: $-5.50 \mathrm{kV}$, capillary temperature: $400{ }^{\circ} \mathrm{C}$, capillary voltage: $-4 \mathrm{~V}$, tube lens: $-86.07 \mathrm{~V}$, data were acquired in profile mode during the liquid chromatography (LC) run. $5 \mathrm{mg}$ of the extract were dissolved in $1 \mathrm{~mL}$ of methanol and $0.5 \mathrm{~mL}$ of this solution was mixed in $0.5 \mathrm{~mL}$ solution containing $0.1 \%$ ammonium hydroxide in water. $3 \mu \mathrm{L}$ of the extract were injected under gradient conditions (solvent $\mathrm{A}=$ water $-0.1 \%$ ammonium hydroxide, solvent $\mathrm{B}=$ methanol $-0.1 \%$ ammonium hydroxide); $\mathrm{B}=5 \%$ at $\mathrm{t}=0 \mathrm{~min} ; \mathrm{B}=10 \%$ at $\mathrm{t}=3 \mathrm{~min}$; $\mathrm{B}=50 \%$ at $\mathrm{t}=28 \mathrm{~min}$ ) at a flow rate of $0.4 \mathrm{~mL} \mathrm{~min}^{-1}$ and full scan mode $(600-950 \mathrm{~m} / z)$. The wavelengths used in UV detection (DAD) were 280, 310, 330 and $360 \mathrm{~nm}$.

\section{HSCCC equipment}

All fractionations were conducted in the P.C. Inc., 
Potomac, MD, USA apparatus, equipped with a triple coil. The $80 \mathrm{~mL}$ column (1.6 mm i.d.) was used, at $860 \mathrm{rpm}$ and flow rate of $2.0 \mathrm{~mL} \mathrm{~min}{ }^{-1}$. In the first fractionation the system was operated in tail-to-head direction with the upper organic phase as mobile phase and in the second purification was operated in head-to-tail direction with the lower aqueous phase as mobile phase.

\section{Preparation of HSCCC solvent system}

The solvent systems tested was EtOAc-BuOH- $\mathrm{H}_{2} \mathrm{O}$ $(2: 8: 10, \mathrm{v} / \mathrm{v})$ and $(3: 7: 10, \mathrm{v} / \mathrm{v})$. The sample were dissolved in a small test tube containing the equilibrated two-phase solvent system. The test tubes were shaken and the compounds allowed to partition between the two phases. Aliquots of each phase were spotted beside each other separately on silica gel thin layer chromatography (TLC) plates (Merck Art. 05554, Darmstadt, Germany), developed with the organic phase of the solvent system butanol-acetic acid-water (B.A.W.) 8:2:10, v/v. The results were visualized under UV light $(\lambda=254 \mathrm{~nm})$.

\section{HSCCC separation procedure}

The EtOAc-BuOH- $\mathrm{H}_{2} \mathrm{O}(2: 8: 10, \mathrm{v} / \mathrm{v})$ system was used in the fractionation of $\mathrm{BuOH}$ extract. The coil was filled with the stationary lower phase and the mobile upper phase was pumped at a flow rate of $2.0 \mathrm{~mL} \mathrm{~min}^{-1}$ after rotation at $860 \mathrm{rpm} .960 .5 \mathrm{mg}$ of the sample was solubilized in $5 \mathrm{~mL}$ of the solvent system $(1: 1, \mathrm{v} / \mathrm{v})$ and the solution was introduced in the coil through a manual sample injection valve using a $5 \mathrm{~mL}$ sample loop after the balance of the phases inside the coil. A total of 100 fractions of $2 \mathrm{~mL}$ each were collected (60 fractions were collected with rotation and 40 fractions with the rotation turned off). The retention of the stationary phase was $68.75 \%$. Fractions $35-40$ obtained in the first countercurrent chromatography (CCC) were resubmitted to a second CCC purification with the same solvent system and ratios $(3: 7: 10, \mathrm{v} / \mathrm{v})$. The mobile phase was the lower aqueous phase and the stationary phase was the organic upper. $160.9 \mathrm{mg}$ of the sample was dissolved in $5 \mathrm{~mL}$ of the solvent system $(1: 1, \mathrm{v} / \mathrm{v})$ and 40 fractions were collected with rotation and 51 fractions with the rotation turned off (flow rate: $2.0 \mathrm{~mL} \mathrm{~min}^{-1} ; 1 \mathrm{~min}$ per fraction). The retention of the stationary phase was $63.75 \%$.

\section{Spectroscopical identification by NMR}

${ }^{1} \mathrm{H}$ and ${ }^{13} \mathrm{C}$ nuclear magnetic resonance (NMR) data for the isolated compound were acquired in deuterated methanol $\left(\mathrm{CD}_{3} \mathrm{OD}\right)$ at $31^{\circ} \mathrm{C}$ (Varian VNMRS $500 \mathrm{MHz}$ spectrometer,
Palo Alto, USA); the $\mathrm{CD}_{3} \mathrm{OD}$ multiplet at $\delta_{\mathrm{H}} 3.31$ and $\delta_{\mathrm{C}} 49.15 \mathrm{ppm}$ was used as chemical shift reference.

\section{HR-ESI-Orbitrap-MS analysis}

The isolated compound was analyzed by high-resolution HR-ESI-Orbitrap-MS on a LQT XL Orbitrap (Thermo Fisher Scientific, Waltham, USA) instrument operating in the negative ion mode. Direct infusion mode: $10 \mu \mathrm{L} \mathrm{min}^{-1}$ diluted with solvent $\mathrm{MeOH}: \mathrm{H}_{2} \mathrm{O}(9: 1)+\mathrm{NH}_{4} \mathrm{OH} 0.1 \%$, sheath gas flow rate: $10 \mathrm{arb}$, auxiliary gas flow rate: 2 arb, sweep gas flow rate: $0 \mathrm{arb}$, spray voltage: $-3.8 \mathrm{kV}$, capillary temperature: $350^{\circ} \mathrm{C}$, capillary voltage: $-30 \mathrm{~V}$, tube lens: $-90 \mathrm{~V} .10 \mathrm{mg}$ of the isolated compound were diluted in $300 \mu \mathrm{L}$ methanol, posteriorly $100 \mu \mathrm{L}$ were diluted with $300 \mu \mathrm{L}$ of $1: 1$ methanol/water with $0.1 \%$ ammonium hydroxide. At the end the solution had concentration of $11 \mu \mathrm{g} \mu \mathrm{L}^{-1}$ and $10 \mu \mathrm{L} \mathrm{min}^{-1}$ were injected by direct infusion.

\section{Results and Discussion}

\section{Analysis by UHPLC-DAD-ESI-MS/MS}

Preliminary analysis of the butanol extract (Table 1) in UHPLC-DAD-ESI-MS/MS unit resolution showed the presence of flavonoids. The major compound (Figure 1) was eluted at $13.3 \mathrm{~min}$ (Figure S31, Supplementary Information section) and other minor flavonoids (Figure 2) were detected between 12 to 18 min (Figure S31). CCC was then used to isolate those flavonoids from the butanol extract of leaves of $P$. regnellii.

\section{Fractionation by HSCCC}

Due to the high polarity of the extract, several ratios of the solvent system EtOAc-BuOH- $\mathrm{H}_{2} \mathrm{O}$ were tested by the test tube partitioning test and the ratios 2:8:10 $(\mathrm{v} / \mathrm{v} / \mathrm{v})$ were chosen for the butanol extract fractionation by HSCCC. ${ }^{5}$ This extract $(960.5 \mathrm{mg})$ was submitted to fractionation using the upper organic phase as mobile phase (normal phase elution mode). Thus, fractions 35-40 (160.9 mg, $\mathrm{V}_{\mathrm{M}}=12 \mathrm{~mL}$ ) (Figure S1) were combined and resubmitted to a second CCC purification where compound $\mathbf{1}$ (Figure 1) was obtained (fractions 18-27, $48.1 \mathrm{mg}, \mathrm{V}_{\mathrm{M}}=20 \mathrm{~mL}$ ) (Figure S2) by adjusting the ratios of the same solvent system to 3:7:10 (v/v/v) and alternating the elution mode to reversed phase exploring the orthogonality within the same system. This strategy aimed to decrease the retention time of the compound of interest. Thus, there was a need to decrease the proportion of butanol in the system and to change elution mode from normal to reversed phase mode. 
Table 1. UHPLC-DAD-ESI-MS/MS analysis of butanol extract

\begin{tabular}{|c|c|c|c|c|}
\hline Peak number & Retention time / min & $\lambda_{\max } / \mathrm{nm}$ & {$[\mathrm{M}-\mathrm{H}]^{-}$} & MS/MS \\
\hline 1 & 12.9 & $274.0 ; 374.0$ & 623.3 & $\begin{array}{c}\text { 477.1 }\left(-\mathrm{C}_{6} \mathrm{H}_{10} \mathrm{O}_{4}\right), \\
315.1\left(-\mathrm{C}_{6} \mathrm{H}_{10} \mathrm{O}_{4}-\mathrm{C}_{6} \mathrm{H}_{10} \mathrm{O}_{5}\right)\end{array}$ \\
\hline 2 & 13.3 & $267.0 ; 354.0$ & 885.1 & $\begin{array}{c}739.1\left(-\mathrm{C}_{6} \mathrm{H}_{10} \mathrm{O}_{4}\right) ; \mathrm{MS}^{3}(739.1): \\
593.2\left(-\mathrm{C}_{6} \mathrm{H}_{10} \mathrm{O}_{4}\right) \\
575.3\left(-\mathrm{H}_{2} \mathrm{O}-\mathrm{C}_{6} \mathrm{H}_{10} \mathrm{O}_{4}\right) \\
285.2\left(-\mathrm{C}_{6} \mathrm{H}_{10} \mathrm{O}_{5}-2 \mathrm{C}_{6} \mathrm{H}_{10} \mathrm{O}_{4}\right) \\
\end{array}$ \\
\hline 3 & 13.7 & $267.0 ; 355.0$ & 685.2 & $604.2,565.1,519.2,504.3,396.1$ \\
\hline 4 & 13.9 & $273.0 ; 366.0$ & 623.3 & $\begin{array}{c}315.0\left(-\mathrm{C}_{6} \mathrm{H}_{10} \mathrm{O}_{4}-\mathrm{C}_{6} \mathrm{H}_{10} \mathrm{O}_{5}\right) \\
300.1\left(-\mathrm{C}_{6} \mathrm{H}_{10} \mathrm{O}_{4}-\mathrm{C}_{6} \mathrm{H}_{10} \mathrm{O}_{5}-\mathrm{CH}_{3}\right)\end{array}$ \\
\hline 5 & 14.1 & $256.0 ; 356.0$ & 915.2 & $\begin{array}{c}769.1\left(-\mathrm{C}_{6} \mathrm{H}_{10} \mathrm{O}_{4}\right) ; \mathrm{MS}^{3}(769.1): \\
623.1\left(-\mathrm{C}_{6} \mathrm{H}_{10} \mathrm{O}_{4}\right) \\
605.2\left(-\mathrm{H}_{2} \mathrm{O}-\mathrm{C}_{6} \mathrm{H}_{10} \mathrm{O}_{4}\right) \\
315.1\left(-2 \mathrm{C}_{6} \mathrm{H}_{10} \mathrm{O}_{4}-\mathrm{C}_{6} \mathrm{H}_{10} \mathrm{O}_{5}\right)\end{array}$ \\
\hline 6 & 16.7 & $267.0 ; 352.0$ & 739.3 & $\begin{array}{c}593.1\left(-\mathrm{C}_{6} \mathrm{H}_{10} \mathrm{O}_{4}\right) ; \mathrm{MS}^{3}(593.1): \\
447.0\left(-\mathrm{C}_{6} \mathrm{H}_{10} \mathrm{O}_{4}\right) \\
285.0\left(-\mathrm{C}_{6} \mathrm{H}_{10} \mathrm{O}_{4}-\mathrm{C}_{6} \mathrm{H}_{10} \mathrm{O}_{5}\right) \\
\end{array}$ \\
\hline 7 & 17.6 & not detected & 673.1 & $511.1,495.1,465.2,375.1,345.3$ \\
\hline 8 & 18.0 & $257.0 ; 351.0$ & 769.3 & $\begin{array}{c}623.1\left(-\mathrm{C}_{6} \mathrm{H}_{10} \mathrm{O}_{4}\right) ; \mathrm{MS}^{3}(623.1): \\
477.3\left(-\mathrm{C}_{6} \mathrm{H}_{10} \mathrm{O}_{4}\right) \\
315.1\left(-\mathrm{C}_{6} \mathrm{H}_{10} \mathrm{O}_{4}-\mathrm{C}_{6} \mathrm{H}_{10} \mathrm{O}_{5}\right) \\
\end{array}$ \\
\hline
\end{tabular}

\section{Characterization of isolated compound}

${ }^{1} \mathrm{H}$ resonances (Figure S3) were found consistent with a 5,7,4'-trisubstituted kaempferol, where two ortho-coupled protons correspond to $\delta_{\mathrm{H}} 8.08(2 \mathrm{H}, \mathrm{d}, J 8.7 \mathrm{~Hz})$ and $6.89(2 \mathrm{H}$, $\mathrm{d}, J 8.5 \mathrm{~Hz}$ ) corresponds to a characteristic para-disubstituted B-ring (AA'BB' system) and two meta-coupled protons at $\delta_{\mathrm{H}} 6.70(\mathrm{~d}, J 1.8 \mathrm{~Hz})$ and $6.44(\mathrm{~d}, J 1.8 \mathrm{~Hz})$ correspond to the meta-disubstituted A-ring (AB system) (Figure $\mathrm{S} 4$ ) (Table 2) ${ }^{6-8}$ Four protons of anomeric carbons (Figure S5) at $\delta_{\mathrm{H}} 5.64(\mathrm{~d}, J 7.7 \mathrm{~Hz}), 5.56(\mathrm{~d}, J 0.8 \mathrm{~Hz}), 5.22(\mathrm{~d}, J 1.0 \mathrm{~Hz})$ and $4.52(\mathrm{~d}, J 1.0 \mathrm{~Hz})$, indicated the presence of four sugar moieties. Those were correlated to carbon resonances at $\delta_{\mathrm{C}}$ 99.4, 98.4, 101.2 and 100.4 ppm (Table 2), respectively, in the heteronuclear single quantum coherence (HSQC) spectra (Figure S22).

The sugar identities were defined using the characteristic behavior of their inner ${ }^{3} J_{\mathrm{HH}}$ under the relayed conditions of the total correlation spectroscopy (2D-TOCSY) experiment. Three deoxyhexoses distinctive methyl resonances at $\delta_{\mathrm{H}}$ $1.26(3 \mathrm{H}, \mathrm{d}, J 6.2 \mathrm{~Hz}), 1.18(3 \mathrm{H}, \mathrm{d}, J 6.1 \mathrm{~Hz})$ and 0.99 $(3 \mathrm{H}, \mathrm{d}, J 6.2 \mathrm{~Hz})$ (Figure S7) and their relayed series of cross-peaks defining $\mathrm{H}_{\text {axial }}-\mathrm{H}_{\text {axial }}$ configuration (H5-H4 and $\mathrm{H} 4-\mathrm{H} 3$ ) were observed leading to the identification of rhamnose moieties by its characteristic H-6 (Table 2). ${ }^{9}$ The axial hydroxy group at $\mathrm{C} 2$ in rhamnose results in a weak $\mathrm{H}_{\text {axial }}-\mathrm{H}_{\text {equatorial }}{ }^{3} J_{\mathrm{HH}}$. H-2, H-3, H-4 and $\mathrm{H}-5$ in the three rhamnose residues and $\mathrm{H}-2, \mathrm{H}-3, \mathrm{H}-4, \mathrm{H}-5$ and $\mathrm{H}-6 \mathrm{a} / \mathrm{H}-6 \mathrm{~b}$ in the glucose residue could be totally distinguished and assigned (Table 2) with sequential correlation spectroscopy (2D-COSY) (Figures S14-S17) and 2D-TOCSY (Figures S18-S21) .

The ${ }^{13} \mathrm{C}$ NMR (Figures S8-S13) displayed 37 carbon signals accordingly to a kaempferol aglycone $\left(\delta_{\mathrm{C}} 178.1\right.$, $161.9,161.5,160.1,157.8,156.4,133.3,130.9$ (2C), 121.3, $114.8(2 \mathrm{C}), 106.0,98.8,94.2)$, one glucose $\left(\delta_{\mathrm{C}} 99.4,76.2\right.$, $74.3,73.9,70.6,65.5)$ and three rhamnoses $\left(\delta_{\mathrm{C}} 101.2,100.4\right.$, 98.4, 72.6, 72.5, 72.0, 70.8, 70.7, 70.6, 70.6, 70.3, 69.9, 69.7, $68.5,68.3,16.7,16.5,16.1$ ) (Table 2). Glycosylation of phenolic hydroxyl group results in changes in the expected ${ }^{13} \mathrm{C}$ resonance of the free aglicone. ${ }^{10}$ The expected resonance values for C-3 and C-7 have shown a shift that was held as evidence to support a 3- and 7-O-glycosylation and later confirmed by long-range correlations in the heteronuclear multiple bond correlation (HMBC) data (Figure S26).

Independent fragments were sequentially attached according to data inferred from long-range correlation using the HMBC. Key correlation peaks were observed between the protons of anomeric carbons of $\mathrm{H}-1$ Gluc $\left(\delta_{\mathrm{H}}\right.$ 5.64) and $\mathrm{H}-1 \mathrm{Rha}(\mathrm{I})\left(\delta_{\mathrm{H}}\right.$ 5.56) and the resonance of C-3 and C-7 at $\delta_{\mathrm{C}} 133.3$ and $\delta_{\mathrm{C}} 161.9 \mathrm{ppm}$, respectively, in the kaempferol aglicone confirming a $3-O-\beta$-glucose and a $7-O-\alpha$-rhamnose as primary sugars. The two rhamnoses, $\mathrm{H}-1$ Rha $(\mathrm{II})\left(\delta_{\mathrm{H}} 5.22\right)$ and $\mathrm{H}$-1Rha (III) $\left(\delta_{\mathrm{H}} 4.52\right)$, were found to be $O$-attached to the C-2 Glu $\left(\delta_{\mathrm{C}} 76.2 \mathrm{ppm}\right)$ and C-6 Glu $\left(\delta_{\mathrm{C}} 65.5 \mathrm{ppm}\right)$ of the primary $3-O-\beta$-glucose residue in a branched trisaccharide structure. The configurations of the anomeric positions were assigned as $\beta, \alpha, \alpha$ and $\alpha$, respectively, from their coupling constants between ring protons $\mathrm{H}-1$ and $\mathrm{H}-2$ assuming the expected D-glucose and L-rhamnose natural forms. 
Table 2. ${ }^{1} \mathrm{H}$ and ${ }^{13} \mathrm{C}$ NMR spectral data for compound 1 (500 MHz, $\left.\mathrm{CD}_{3} \mathrm{OD}\right)$

\begin{tabular}{|c|c|c|}
\hline & $\begin{array}{c}{ }^{1} \mathrm{H} \delta / \text { ppm mult. } \\
\quad(J \text { in } \mathrm{Hz})\end{array}$ & ${ }^{13} \mathrm{C} \delta / \mathrm{ppm}$ \\
\hline \multicolumn{3}{|c|}{ Kaempferol moiety } \\
\hline 2 & & 157.8 \\
\hline 3 & & 133.3 \\
\hline 4 & & 178.1 \\
\hline 5 & & 161.5 \\
\hline 6 & $6.44 \mathrm{~d}(1.9)$ & 98.8 \\
\hline 7 & & 161.9 \\
\hline 8 & $6.70 \mathrm{~d}(1.9)$ & 94.2 \\
\hline 9 & & 156.4 \\
\hline 10 & & 106.0 \\
\hline $1^{\prime}$ & & 121.3 \\
\hline $2^{\prime}, 6^{\prime}$ & $8.08 \mathrm{~d}(8.7)$ & 130.9 \\
\hline $3^{\prime}, 5^{\prime}$ & $6.89 \mathrm{~d}(8.7)$ & 114.8 \\
\hline $4^{\prime}$ & & 160.1 \\
\hline \multicolumn{3}{|c|}{ 3-O- $\beta$-Glucose } \\
\hline $1 "$ & $5.64 \mathrm{~d}(7.7)$ & 99.4 \\
\hline $2 "$ & $3.95 \mathrm{dd}(9.5,7.7)$ & 76.2 \\
\hline $3 "$ & $3.73 \mathrm{dd}(9.5,9.5)$ & 74.3 \\
\hline $4 "$ & $3.56(\mathrm{~m})^{\mathrm{a}}$ & 70.6 \\
\hline $5 "$ & $3.67(\mathrm{~m})^{\mathrm{a}}$ & 73.9 \\
\hline $6 a "$ & $3.46 \mathrm{dd}(10.0,2.1)$ & 65.5 \\
\hline $6 \mathrm{~b} "$ & $3.73(\mathrm{~m})^{\mathrm{a}}$ & \\
\hline \multicolumn{3}{|c|}{ 7-O- $\alpha$-Rhamnose (I) } \\
\hline $1, "$, & $5.56 \mathrm{~d}(0.8)$ & 98.4 \\
\hline $2, "$, & $4.03 \mathrm{dd}(3.2,0.8)$ & 70.3 \\
\hline $3, "$, & $3.80(\mathrm{~m})^{\mathrm{a}}$ & 70.7 \\
\hline $4, "$, & $3.35 \mathrm{dd}(9.9,9.9)$ & 72.0 \\
\hline $5, "$, & $3.55(\mathrm{~m})^{\mathrm{a}}$ & 69.7 \\
\hline $6, "$, & $1.26 \mathrm{~d}(6.2)$ & 16.7 \\
\hline \multicolumn{3}{|c|}{$2^{\text {Gluc }}-O$ - $\alpha$-Rhamnose (II) } \\
\hline $1 "$, & $5.22 \mathrm{~d}(1.0)$ & 101.2 \\
\hline $2 "$, & $4.01 \mathrm{dd}(3.1,1.0)$ & 70.8 \\
\hline $3 "$, & $3.31(\mathrm{~m})^{\mathrm{a}}$ & 70.6 \\
\hline $4 "$, & $3.74 \mathrm{dd}(9.3,9.3)$ & 72.6 \\
\hline $5 "$ & $4.10 \mathrm{dq}(9.3,6.2)$ & 68.5 \\
\hline $6 "$, & $0.99 \mathrm{~d}(6.2)$ & 16.1 \\
\hline \multicolumn{3}{|c|}{$6^{\text {Gluc }} O-O$ - $\alpha$-Rhamnose (III) } \\
\hline $1, "$, & $4.52 \mathrm{~d}(1.0)$ & 100.4 \\
\hline $2 "$, & $3.55 \mathrm{dd}(3.4,1.0)$ & 70.6 \\
\hline $3 "$, & $3.47 \mathrm{dd}(3.4,9.4)$ & 68.3 \\
\hline $4, "$, & 3.26 dd $(9.4,9.4)$ & 72.5 \\
\hline $5, "$, & $3.53 \mathrm{dq}(9.4,6.1)$ & 69.9 \\
\hline $6 ", "$ & $1.18 \mathrm{~d}(6.1)$ & 16.5 \\
\hline
\end{tabular}

$\mathrm{a}(\mathrm{m})$ : overlap.
The major compound in the butanol extract was therefore identified as kaempferol $3-O-\beta-\mathrm{D}$ glucopiranosyl- $(1 \rightarrow 2)$ - $\alpha$-L-rhamnopiranoside$(1 \rightarrow 6)$ - $\alpha$-L-rhamnopiranoside-7- $O-\alpha$-L-rhamnopiranoside (Figure 1). The molecular formula of $\mathrm{C}_{39} \mathrm{H}_{50} \mathrm{O}_{23}$, as deduced from the signal at $m / z 885.26591$ (calculated for $\mathrm{C}_{39} \mathrm{H}_{49} \mathrm{O}_{23}$ $[\mathrm{M}-\mathrm{H}]^{-}:$885.26498; error: $-1.06 \mathrm{ppm}$; ring doble bond (RDB) 15.5) in the negative ion HR-ESI-Orbitrap-MS spectrum. ESI-MS/MS (Figure S30) displayed fragments at $m / z 739.54547[\mathrm{M}-\mathrm{H}-145.71951]^{-}, \mathrm{m} / \mathrm{z} 593.45456$ $[\mathrm{M}-\mathrm{H}-145.71951-146.09091]^{-}$and $\mathrm{m} / \mathrm{z}, 285.27273$ [M-H-145.71951-145.71951-146.09091-162.46232] $]^{-}$ corresponding to the neutral loss of a three rhamnoses and one glucose. The compound showed UV $\left(\lambda_{\max } 267.0\right.$, $354.0 \mathrm{~nm}$ ) (Figure S28), melting point: $80-100^{\circ} \mathrm{C}$ and optical rotatory dispersion (ORD) $(c 1.51, \mathrm{MeOH})[\alpha]_{\mathrm{D}}^{25}-81.676$.

\section{Identification of minor flavonoids by UHPLC-DAD-ESI-MS/ MS}

Minor flavonoids were observed in the butanol extract by using UHPLC-DAD-ESI-MS/MS (Table 1). Based on the identification of the isolated compound it was possible to make assumptions for the identity of the aglycones for five of these compounds. Ultraviolet spectra of all peaks (Table 1) indicated the presence of bands II (ring A) and I (ring B) characteristic for flavonols. ${ }^{9}$

Mass spectra of peaks 1 (12.9 min) (Figure S32) and 4 (13.9 $\mathrm{min}$ ) (Figure S34) showed a signal at $\mathrm{m} / \mathrm{z}, 623.3$ $[\mathrm{M}-\mathrm{H}]^{-}$. Peak 1 displayed a fragment at $\mathrm{m} / \mathrm{z} 477.1$ $[\mathrm{M}-\mathrm{H}-146]^{-}$loss of a deoxyhexose and $\mathrm{m} / \mathrm{z} 315.1$ $[\mathrm{M}-\mathrm{H}-146-162]^{-}$loss of a deoxyhexose and hexose. The fragments corresponding to peak 4 are $\mathrm{m} / \mathrm{z} 315.0$ [M $-\mathrm{H}-146-162]^{-}$corresponding to the loss of a deoxyhexose and hexose, and $\mathrm{m} / z 300.1[\mathrm{M}-\mathrm{H}-146-$ $162-15]^{-}$with the loss of a deoxyhexose, hexose and methyl group. The compounds at these peaks were found to be isomers which can be either a diglycosylated flavonol derived from rhamnetin, 3-O-methyl-quercetin ether or isorhamnetin (Figure 2).

Peak 5 (14.1 min) showed ion [M - H] $]^{-}$with $\mathrm{m} / \mathrm{z} 915.2$ (Figure S36). After ESI-MS/MS experiment it was possible to observe a fragment with $\mathrm{m} / z$ 769.1 [M $-\mathrm{H}-146]^{-}$ corresponding to the loss of a deoxyhexose. $\mathrm{MS}^{3}$ experiment of the ion at $\mathrm{m} / \mathrm{z} 769.1$ showed fragments at $m / z 623.1[\mathrm{M}-\mathrm{H}-146]^{-}, \mathrm{m} / \mathrm{z} 605.2[\mathrm{M}-\mathrm{H}-18-146]^{-}$ and $m / z 315.1[\mathrm{M}-\mathrm{H}-2 \times 146-162]^{-}$corresponding to the cleavage of the two deoxyhexoses and one hexose. The compounds can be either a tetraglycosylated rhamnetin, 3-O-methyl-quercetin ether or isorhamnetin (Figure 2). 
The compound in peak 6 (16.7 $\mathrm{min})$ showed ion $[\mathrm{M}-\mathrm{H}]^{-}$with $\mathrm{m} / \mathrm{z} 739.3$ (Figure S38) and the same aglycone as the isolated compound (Figure 1). ESI-MS/MS spectrum showed fragment at $\mathrm{m} / z 593.1[\mathrm{M}-\mathrm{H}-146]^{-}$ corresponding to the loss of deoxyhexose. After $\mathrm{MS}^{3}$ experiment of ion at $\mathrm{m} / \mathrm{z} 593.1$ it was possible to observe fragments at $m / z 447.0[\mathrm{M}-\mathrm{H}-146]^{-}$and $\mathrm{m} / \mathrm{z} 285.0$ $[\mathrm{M}-\mathrm{H}-146-162]^{-}$including loss of two deoxyhexoses and one hexose. The compound can be a triglycosylated kaempferol (Figure 2).

Ion $[\mathrm{M}-\mathrm{H}]^{-}$with $\mathrm{m} / \mathrm{z} 769.3$, in peak $8(18.0 \mathrm{~min})$ (Figure S40), presented the same aglycone as the compounds in peaks 1, 4 and 5. A fragment at $m / z 623[\mathrm{M}-\mathrm{H}-146]^{-}$ corresponding to the loss of deoxyhexose was observed in ESI-MS/MS spectrum. Upon MS $^{3}$ experiment of the ion at $\mathrm{m} / \mathrm{z}$ 623.1, the spectrum showed fragments at $\mathrm{m} / \mathrm{z}$. $477.3[\mathrm{M}-\mathrm{H}-146]^{-}$and $315.1[\mathrm{M}-\mathrm{H}-146-162]^{-}$ corresponding to the loss two deoxyhexoses and one hexose. The compounds can be either triglycosylated derivatives of rhamnetin, 3-O-methyl-quercetin ether or isorhamnetin (Figure 2).

\section{Conclusions}

Flavonoids are secondary metabolites widely distributed in flowering plants and can occur as free or glycosylated (C-glycosides or $O$-glycosides) derivatives. ${ }^{11,12}$ Considering the sub-class of flavonols, kaempferol and quercetine $O$-glucosides are the most abundant in plants, being either monosaccharides, disaccharides, trisaccharides or tetrasaccharides. ${ }^{13}$ A longer sugar chain in flavonoids is not a common feature. ${ }^{13}$ Through literature search, few flavonol glycosides with $O$-linked tetrasaccharides are reported. These compounds usually bear $O$-glycosilation at the $\mathrm{C}-3$ or $\mathrm{C}-7$ carbon of the aglycone. Of the different branched tetrasaccharides reported as 3-O-glycosides of kaempferol, $\beta$-glucose and $\beta$-galactose are the commonest primary sugars, being $\alpha$-rhamnose linked to the primary sugar at $\mathrm{C}-2$ or $\mathrm{C}-6 .^{14-16}$

In this study, the versatility of the CCC technique was evidenced in the isolation of a high polarity compound from Platycyamus regnellii by slightly modifying the ratio of solvents in the EtOAc-BuOH- $\mathrm{H}_{2} \mathrm{O}$ solvent system and alternating normal and reversed phase $\mathrm{CCC}$ elution modes in each of the separations. Spectrometric and spectroscopic techniques (MS, ${ }^{1} \mathrm{H},{ }^{13} \mathrm{C}, \mathrm{COSY}$, HSQC, HMBC, UV and infrared) enabled the characterization of this compound as kaempferol 3-O- $\beta$-D-glucopiranosyl$(1 \rightarrow 2)$ - $\alpha$-L-rhamnopiranoside- $(1 \rightarrow 6)$ - $\alpha$-L-rhamnopiranoside-7- $O-\alpha$-L-rhamnopiranoside, a new kaempferol tetraglycoside.

\section{Supplementary Information}

Supplementary data associated with this article can be found free of charge at http://jbcs.sbq.org.br as PDF file.

\section{Acknowledgments}

C. M. L. is grateful to the scholarship provided by CAPES, DPNA-UFRJ and INT-RJ for all analyzes. G. G. L. is grateful to CNPq and FAPERJ for funding. Authors are grateful to Prof Rogelio Pereda-Miranda (Facultad de Química, Universidad Nacional Autónoma de Mexico) for his contribution to the interpretation of 2D NMR spectra.

\section{References}

1. Machado, L. M. V.: Estudo Fitoquimico das Raizes de Platycyamus regnellii; Dissertação de Mestrado, Universidade Estadual de Campinas, Campinas, Brasil, 2000, p. 1-103, available at http://www.repositorio.unicamp.br/handle/ REPOSIP/249950 accessed in June 2019.

2. Moura, T. M.; Lewis, G. P.; Tozzi, G. A.; Kew Bull. 2016, 71, 2.

3. Berthod, A.; Maryutina, T.; Spivakov, B.; Shpigun, O.; Sutherland, I. A.; Pure Appl. Chem. 2009, 81, 355.

4. Marston, A.; Hostettmann, K.; J. Chromatogr. A 2006, 1112, 181.

5. Costa, F. N.; Leitão, G. G.; J. Sep. Sci. 2010, 33, 336.

6. Silva, T. M. S.; de Carvalho, M. G.; Braz-Filho, R.; Quim. Nova 2009, 32, 1119.

7. Pizzolatti, M. G.; Cunha Jr., A.; Szpoganicz, B.; Sousa, E.; Quim. Nova 2003, 26, 466.

8. Harbone, J. B.; Mabry, T. J.; Mabry, H. In The Flavonoids; Academic Press: New York, 1975.

9. Mabry, T. J.; Markham, K.; Thomas, M. B.; The Systematic Identification of Flavonoids; Springer-Verlag: New York, 1970.

10. Agrawal, P. K.; Bansal, M. C. In Carbon-13 NMR of Flavonoids, vol. 39; Agrawal, P. K., ed.; Elsevier Science Publishers B.V.: Amsterdam, 1989.

11. Kumar, S.; Pandey, A. K.; Sci. World J. 2013, ID 162750.

12. Veitch, N. C.; Bristow, J. M.; Kite, G. C.; Lewis, G. P.; Tetrahedron Lett. 2005, 46, 8595.

13. Yang, B.; Liu, H.; Yang, J.; Gupta, V. K.; Jiang, Y.; Trends Food Sci. Technol. 2018, 79, 116.

14. Veitch, N. C.; Grayer, R. J.; Nat. Prod. Rep. 2008, 25, 555.

15. Kite, G. C.; Stoneham, C. A.; Veitch, N. C.; Phytochemistry 2007, 68, 1407.

16. Kite, G. C.; Veitch, N. C.; Soto-Hernàndez, M.; Lewis, G. P.; S. Afr. J. Bot. 2013, 89, 181.

Submitted: March 14, 2019

Published online: June 21, 2019 